\title{
Lymphoedema of the limbs as an extra-articular feature of rheumatoid arthritis
}

Department of Rheumatology, St Bartholomew's and Homerton Hospitals, West Smithfield, London EC1A 7 BE J E Dacre D L Scott

E C Huskisson

Correspondence to: Dr Dacre.

Accepted for publication 13 October 1989

\begin{abstract}
Seven patients with lymphoedema of the hands and arms, an unusual extra-articular feature of rheumatoid arthritis, are described. In all cases the lymphoedema persisted throughout follow up-in one case for more than five years - and was resistant to treatment with slow acting drugs, steroids, or cytotoxic agents. There was no correlation with severity of disease. It is concluded that the lymphoedema in these patients may be associated with reduced numbers of lymphatic vessels; increased capillary permeability or abnormal fibrinolysis may also be contributory factors. Conservative management of such patients is recommended.
\end{abstract}

Patients with rheumatoid arthritis (RA) characteristically present with painful swollen hands and feet due to synovitis of their small joints. Lymphoedema of the limbs can be an added complication in a small number of cases. Lymphoedema of the upper limbs was first reported in RA by Kalliomaki and Vastamaki in 1968. ' Dudley Hart subsequently mentioned three cases in a review of the extra-articular features of RA. ${ }^{2}$ Since then there have been three further reports, ${ }^{3-5}$ and altogether 16 patients have been described. We have seen seven patients with this complication and report their clinical course, together with a review of the published findings.

\section{Case reports}

A synopsis of the patients studied is given in table 1 .

CASE 1

A 57 year old motor mechanic presented with painful swollen hands and prolonged morning stiffness which he had had for six weeks. He had no neurological symptoms. Examination showed bilateral lymphoedema of the hands that extended to his wrists and inflammatory arthritis of the metacarpophalangeal joints. He had previously had polymyalgia rheumatica, which had been treated with steroids. He had concomitant diabetes mellitus and ischaemic heart disease. Tests for rheumatoid factor were negative and his erythrocyte sedimentation rate (ESR) was $35 \mathrm{~mm} /$ first hour. Radiographs of his hands showed an erosive arthritis. Seronegative RA was diagnosed. He was treated with indomethacin and showed symptomatic improvement. The lymphoedema persisted. No other antirheumatic drugs were given.

\section{CASE 2}

A 52 year old photographer had a 10 year history of classic RA of polymyalgic onset. He had coexistent benign paraproteinaemia. He presented with a two year history of increased pain in his wrists and hands associated with diffuse swelling and considerable morning stiffness. Examination showed bilateral lymphoedema of hands and forearms in association with active synovitis and pronounced joint destruction. Tests for rheumatoid factor were positive; the ESR was $64 \mathrm{~mm} /$ first hour. Radiographs of his hands showed symmetrical erosive changes. Electrophoresis showed an IgM monoclonal gammopathy. There was no evidence of lymphoma or myeloma despite extensive investigation. Lymphangiography was undertaken with difficulty and showed no definite abnormality. He had previously been treated with gold and penicillamine with no alleviation of his symptoms. Subsequently treatment with hydroxychoroquine, prednisolone, and cyclophosphamide was unsuccessful. At the time of writing he was receiving sulphasalazine. The lymphoedema persists (figure), though it has shown some improvement.

Table 1 Synopsis of patients with lymphoedema studied

\begin{tabular}{|c|c|c|c|c|c|c|c|}
\hline & \multicolumn{7}{|l|}{ Case No } \\
\hline & 1 & 2 & 3 & 4 & 5 & 6 & 7 \\
\hline $\begin{array}{l}\text { Age in years when seen } \\
\text { Sex } \\
\text { Site of lymphoedema } \\
\text { Onset of lymphoedema after RA (years) } \\
\text { Rheumatoid factor } \\
\text { Antinuclear antibody } \\
\text { ESR } \\
\text { Radiology } \\
\text { Outcome }\end{array}$ & $\begin{array}{l}57 \\
\text { M } \\
\text { Hands } \\
<1 \\
\text { Negative } \\
\text { Negative } \\
\text { High } \\
\text { Erosions } \\
\text { Minor improvement }\end{array}$ & $\begin{array}{l}52 \\
M \\
\text { Hands } \\
8 \\
\text { Positive } \\
\text { Negative } \\
\text { Very high } \\
\text { Erosions } \\
\text { Minor improvement }\end{array}$ & $\begin{array}{l}44 \\
M \\
\text { Hands } \\
1 \\
\text { Positive } \\
\text { Positive } \\
\text { High } \\
\text { No erosions } \\
\text { No change }\end{array}$ & $\begin{array}{l}51 \\
\text { F } \\
\text { Hands } \\
<2 \\
\text { Negative } \\
\text { Positive } \\
\text { Low } \\
\text { Erosions } \\
\text { No change }\end{array}$ & $\begin{array}{l}45 \\
\text { F } \\
\text { Hands } \\
2 \\
\text { Positive } \\
\text { NK } \\
\text { High } \\
\text { Erosions } \\
\text { No change }\end{array}$ & $\begin{array}{l}62 \\
\text { M } \\
\text { Hands } \\
5 \\
\text { Negative } \\
\text { Negative } \\
\text { High } \\
\text { Erosions } \\
\text { No change }\end{array}$ & $\begin{array}{l}54 \\
\text { F } \\
\text { Feet } \\
<1 \\
\text { Positive } \\
\text { Negative } \\
\text { High } \\
\text { Erosions } \\
\text { No change }\end{array}$ \\
\hline
\end{tabular}




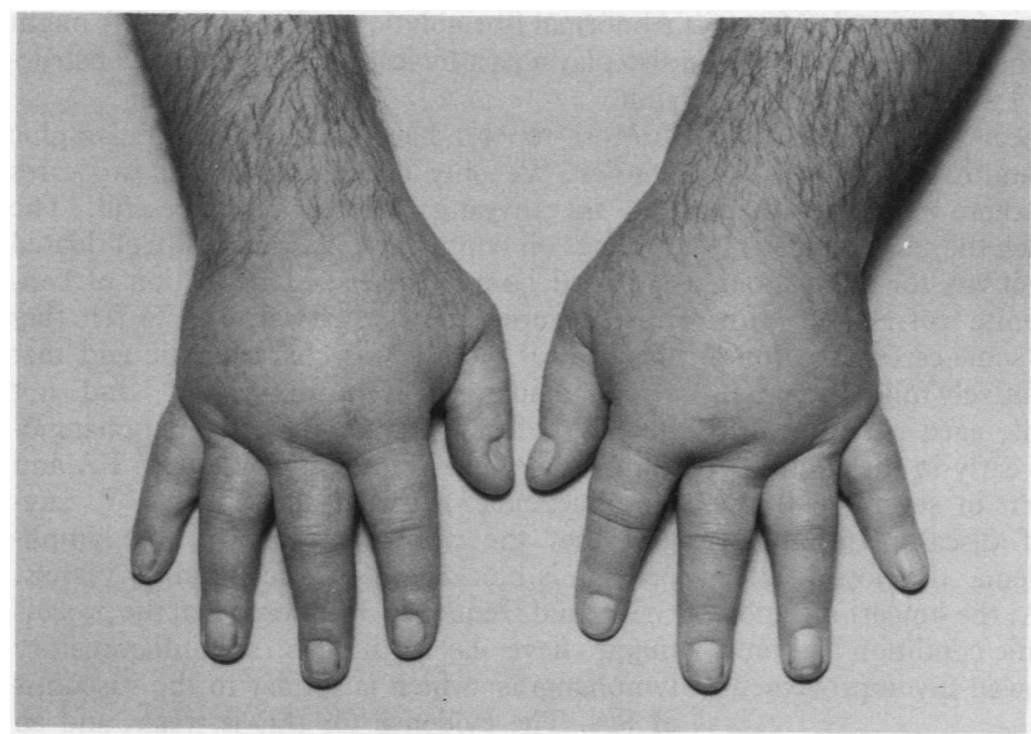

Hands of one rheumatoid patient with lymphoedema (case 2).

CASE 3

A 44 year old publican presented with 18 months of swollen stiff hands He had some pain when first seen. This resolved, leaving persistent bilateral lymphoedema of both hands and wrists that extended to the left elbow. Tests for rheumatoid factor were initially negative but subsequently became positive. His ESR was 45 $\mathrm{mm}$ /first hour. Radiographs showed soft tissue swelling and periarticular osteoporosis without erosions. RA was diagnosed. Non-steroidal anti-inflammatory drugs were of minimal value, but he has not needed additional treatment. His lymphoedema persists.

\section{CASE 4}

A 51 year old woman with an 11 year history of classic RA developed painful swollen hands. Examination showed bilateral lymphoedema. She had previously been treated with levamisole, but had relapsed, and, at the time of writing, was currently controlled on auranofin. Her ESR was $10 \mathrm{~mm} /$ first hour and she was rheumatoid factor negative. Radiographs of her hands showed fusion of both wrists joints with erosions affecting the metacarpophalangeal joints. She also had atlantoaxial subluxation. The lymphoedema subsequently persisted for more than five years without regression.

\section{CASE 5}

A 45 year old woman with a 10 year history of classic RA presented with an eight year history of a swollen right hand. Examination showed unilateral lymphoedema of the right hand with bilateral synovitis of the metacarpophalangeal joints. At presentation she was treated with azathioprine and has continued receiving that treatment. Her ESR was $50 \mathrm{~mm} /$ first hour; tests for rheumatoid factor were positive. Radiographs of her hands showed moderately severe erosive changes. The lymphoedema has been resistant to treatment.

CASE 6

A 62 year old greengrocer presented with three years of polyarthritis which was diagnosed as RA. Most peripheral joints were affected. He had had a history of Raynaud's phenomenon since the age of 16. At presentation he had pronounced lymphoedema of the left hand and forearm and the right hand. Radiography showed that this was an erosive arthritis. He was seronegative for rheumatoid factor and also negative for antinuclear antibodies. The ESR varied from 2 to $20 \mathrm{~mm}$ /first hour. A lymphangiogram showed no abnormality. The arthritis went into remission with non-steroidal antiinflammatory drugs alone but the lymphoedema of his hands has persisted.

CASE 7

A 54 year old housewife developed acute polyarthritis in 1983 with the typical symmetrical and widespread distribution of RA. She had associated Raynaud's phenomenon. She had a severely swollen right foot. Over the next few months she developed bilateral lymphoedema of the feet extending up to the mid-calf. This varied in severity over the ensuing years. There was no evidence of venous thrombosis. Investigations showed an ESR of $30 \mathrm{~mm} /$ first hour which subsequently rose to $>100 \mathrm{~mm} /$ hour, remaining high. She was seropositive for rheumatoid factor. Tests for antinuclear antibodies and extractable nuclear antibodies were consistently negative. Radiographs showed widespread rheumatoid erosions. She received non-steroidal anti-inflammatory drugs, tetracosactrin acetate, and several slow acting drugs, including penicillamine and chlorambucil. Her RA remained active and the lymphoedema persisted. In 1986 she developed radiological atlantoaxial subluxation.

\section{Discussion}

Lymphoedema of the upper limbs is a rare extra-articular feature of RA. It can also affect the lower limbs, as shown in our final case (case 7 ), and those reported by Dudley Hart ${ }^{2}$ and

Table 2 Summary of six reports of hymphoedema in RA

\begin{tabular}{|c|c|c|c|c|c|c|c|}
\hline Report & Year & $\begin{array}{l}\text { Number } \\
\text { of cases }\end{array}$ & $M / F$ & $\begin{array}{l}\text { Mean age } \\
\text { in years }\end{array}$ & $\begin{array}{l}\text { Mean disease } \\
\text { duration in years }\end{array}$ & $\begin{array}{l}\text { Rhewomatoid } \\
\text { factor }\end{array}$ & Outcome \\
\hline $\begin{array}{l}\text { Kallomaki et al }{ }^{1} \\
\text { Dudley Hart } \\
\text { De Silva et } a b^{3} \\
\text { Kyle et ab́l } \\
\text { Grillet } e t a l^{4} \\
\text { This report }\end{array}$ & $\begin{array}{l}1968 \\
1969 \\
1980 \\
1982 \\
1987 \\
1989\end{array}$ & $\begin{array}{l}2 \\
3 \\
7 \\
1 \\
3 \\
7\end{array}$ & $\begin{array}{l}0 / 2 \\
\text { NK } \\
\text { NK } \\
1 / 0 \\
3 / 0 \\
3 / 4\end{array}$ & $\begin{array}{l}48 \\
\text { NK } \\
51 \\
40 \\
52 \\
52\end{array}$ & $\begin{array}{l}5 \\
\text { NK } \\
7 \\
3 \\
5 \\
3\end{array}$ & $\begin{array}{l}2 \\
\text { NK } \\
3 \\
1 \\
1 \\
4\end{array}$ & $\begin{array}{l}\text { Neither improved } \\
\text { One case improved } \\
\text { One case improved } \\
\text { No improvement } \\
\text { One case improved } \\
\text { Two cases improved }\end{array}$ \\
\hline
\end{tabular}


Grillet et al. ${ }^{4}$ A summary of the details of our own patients and those of the previously reported cases is shown in table 2 . Twenty three patients with lymphoedema have been described: in 19 it affected the upper limbs and in four the legs. It is more common in men; there were seven men out of the 13 cases for which the sex was known. It is not related to seropositivity for rheumatoid factor. There is no definite correlation with disease activity; although some cases have quite active RA, others have relatively mild disease. It usually develops in middle aged patients with RA. Sometimes it occurs early in the course of RA, and it has been seen in several patients within the first year of disease. In others, however, the lymphoedema developed after more than a decade of RA; the longest duration was 12 years. It is a chronic condition and only five out of the 23 cases showed any improvement with time and treatment.

The first report by Kalliomaki and Vastamaki described two Finnish women in middle age with seropositive RA. ${ }^{1}$ Their lymphoedema showed no obvious response to diuretics, steroids, or other drugs. These workers used lymphoscintigraphy with radiolabelled colloidal gold; the colloidal gold is injected subcutaneously and enters the lymph ducts and passes on to the regional lymph nodes. ${ }^{6}$ In normal subjects active accumulation is seen in the axillary nodes. Kalliomaki and Vastamaki found no uptake of colloidal gold in the axillary nodes of the affected side, which suggested a local lymphatic blockage.

In some patients other mechanisms may lead to swelling of the forearms. Macfarlane and Van der Linden have described swelling in one man due to leaking olecranon bursitis. ${ }^{7}$ McCarty et al have reported pitting oedema in remitting seronegative symmetrical synovitis. ${ }^{8}$ These patients have different problems from the 23 patients with lymphoedema, and the changes might have reflected other pathological mechanisms. There may, however, be some features in common; our first patient had diabetes mellitus and the second patient an IgM paraprotein, and both of these might have contributed to increased lymphatic permeability and part of the upper limb swelling. Jayson and Barkes have shown that there are changes in capillary permeability in RA with increased filtration of tissue fluid. ${ }^{9}$ In some cases this might have contributed towards the lymphoedema.
Abnormal fibrinolytic mechanisms in RA might also play a part by leading to lymphatic obstruction.

Most reports have included lymphographic studies. We only undertook this in two cases and the investigation was unsuccessful. The findings on lymphography are usually of dilated proximal lymph vessels, extravasation of contrast material and dermal reflux. We felt that the clinical picture was characteristic and that lymphangiograms were unpleasant, and not necessary for management. The lymphangiograms undertaken in the patients with RA and lymphoedema reported previously ${ }^{13-5}$ suggest that the principal cause of the lymphoedema is blockage of the deep lymph vessels. Grillet and Dequeker considered that the process might have been due to an inflammatory lymphangitis, which is similar to the vasculitis of RA. The evidence for this is weak, and an alternative possibility is that there are reduced numbers of lymphatics in rheumatoid patients, which can readily become obstructed by fibrin and related products. In either case there is no definite improvement after aggressive treatment with steroids, slow acting antirheumatic drugs, and cytotoxic agents. We recommend conservative management of such patients with limited investigation.

We thank the Arthritis and Rheumatism Council and the Joint Research Board of St Bartholomew's Hospital for their support. Dr Dacre is an ARC Research Fellow. Dr Scott is the Muir Hambro Research Fellow of the Royal College of Physicians. We Hambro Research Fellow of the Royal College of Physicians. We
thank Dr D V Doyle and Dr J Lanham for allowing us to report thank Dr D
their cases.

1 Kalliomaki J L, Vastamaki M. Chronic diffuse oedema of the rheumatoid hand: a sign of local lymphatic involvement. Ann Rheum Dis 1968; 27: 167-9.

2 Hart F D. Rheumatoid arthritis: extra-articular manifestations. Br Med F 1969; iii: 131-6.

3 De Silva R T D, Grennan D M, Palme D. Lymphatic obstruction in rheumatoid arthritis: a cause for upper limb oedema. Ann Rheum Dis 1980; 39: 260-5.

4 Grillet D, Dequeker J. Rheumatoid lymphoedema. I Rheu-

matol 1987; 14: 1095-6.
5 Kyle V M, De Silva M, Hurst G. Rheumatoid lymphoedema. Clin Rheumatol 1892; 1: 126.

6 Sage H H, Sinba B K, Kizilay D, Toulon R. Radioactive colloidal gold measurements of lymph flow and functional patterns of lymphatics and lymph nodes in the extremities. f Nucl Med 1964; 5: 626-30.

7 Macfarlane J D, Van-der-Linden S J. Leaking rheumatoid olecranon bursitis as cause of forearm swelling. Ann Rheum Dis 1981; 40: 309-11.

8 McCarty D J, O'Duffy J D, Pearson L, Hunter J B. Remitting seronegative symmetrical synovitis with pitting oedema. FAMA 1985; 954: 2763-7.

9 Jayson M I, Barks J S. Oedema in rheumatoid arthritis: changes in the coefficient of capillary filtration. $\mathrm{Br} \mathrm{Med} \mathcal{F}$ 1971; ii: 555-7. 